\title{
A demanda de reparação - a vítima como figura emblemática na contemporaneidade ${ }^{1}$
}

\section{The demand for reparation - victimization in contemporary society}

\section{La exigencia de reparación - la víctima como figura emblemática de la contemporaneidad}

\author{
I ngrid Vorsatz* \\ Universidade do Estado do Rio de Janeiro - UERJ, Rio de Janeiro, Brasil \\ Marcos Eichler de Almeida Silva** \\ Universidade do Estado do Rio de Janeiro - UERJ, Rio de Janeiro, Brasil
}

\begin{abstract}
RESUMO
O presente artigo pretende discutir a noção de vítima enquanto figura emblemática do laço social que sobrevém na modernidade, de modo a pôr em causa a tessitura que ampara a constituição da legitimidade culturalmente atribuída desse lugar, bem como analisar as consequências discursivas e subjetivas então decorrentes. Partindo-se desta discussão conceitual, pretende-se ainda investigar a contribuição própria ao discurso psicanalítico na escuta dos casos de suspeita de violência sexual contra crianças e adolescentes, sobretudo em sua vertente intrafamiliar, problematizando, deste modo, a questão da vitimização e suas implicações no endereçamento ao campo da Assistência Social.

Palavras-chave: psicanálise, contemporaneidade, vítima, reparação.
\end{abstract}

\section{ABSTRACT}

The paper discusses the victim as an iconic figure of the social bonding that arises in modernity, in order to unravel the vectors that support this position's culturally attributed legitimacy, as well as to analyze the ensuing discursive and subjective consequences. Starting from this conceptual discussion, the authors intend to investigate the specific contribution of the psychoanalytical discourse to the listening of cases of suspected sexual violence, especially in their domestic aspect, against children and adolescents, thus problematizing the question of victimization and its implications in the field of Social Work.

Keywords: psychoanalysis, contemporary, victim, reparation.

\section{RESUMEN}

El artículo discute la víctima como figura emblemática del lazo social que ocurre en la modernidad y sus implicaciones desde el psicoanálisis, poniendo en cuestión lo que constituí la legitimidad culturalmente atribuida de ese lugar, así como analizar las consecuencias discursivas y subjetivas que se derivan. A partir de esta discusión conceptual, se pretende aún investigar la 
contribución del discurso psicoanalítico en los casos de sospecha de violencia sexual hacia niños y jóvenes, sobretodo en su vertiente intrafamiliar, problematizando de este modo la cuestión de la victimización y sus implicaciones en el campo de la Asistencia Social.

Palabras-clave: psicoanálisis, contemporaneidad, víctima, reparación.

\section{I ntrodução}

A figura da vítima tornou-se a metáfora de nossa condição moderna. Antoine Garapon, 2001

O presente artigo pretende discutir a noção de vítima enquanto figura emblemática do laço social que sobrevém na modernidade, de modo a pôr em causa a tessitura que ampara a constituição da legitimidade desse lugar culturalmente atribuído, bem como analisar as consequências discursivas e subjetivas que the são decorrentes. Partindo-se desta discussão conceitual, pretende-se, ainda, investigar a contribuição própria ao discurso psicanalítico na escuta dos casos de suspeita de violência sexual contra crianças e adolescentes, sobretudo em sua vertente intrafamiliar, problematizando, assim, a questão da vitimização e suas implicações no campo da Assistência Social.

A Modernidade, uma das consagradas maneiras de formular a periodização histórica, desde o ponto de vista da cultura ocidental, constituindo-se como um marco cronológico concernente a transformações sociais, políticas, econômicas, ambientais, científicas e tecnológicas, consistindo também na instauração de uma nova modalidade de laço social, sobrevinda com o advento da Ciência Moderna. Tal novidade se explicita na formulação de Lacan (1998b, p.870) o qual assevera que a Ciência Moderna instaura um momento inaugural em que se apresenta como "radical uma modificação em nossa posição de sujeito, no duplo sentido: de que ela é inaugural nesta e de que a Ciência a reforça cada vez mais". Em outras palavras, a operação de fundação da Ciência Moderna põe em jogo uma nova modalidade de sujeito, em "um momento historicamente definido [...] o que foi inaugurado por Descartes e que é chamado cogito" (Lacan, 1998b, p.870). É o recolhimento, por Freud, deste sujeito - estabelecido por Lacan como "correlato antinômico" (Lacan, 1998b, p.875) da Ciência - que virá a articular, alguns séculos depois, a fundação da Psicanálise.

Koyré (1982), numa chave distinta, mas proximamente relacionada, afirma que o advento da Ciência Moderna constitui uma revolução do pensamento, demonstrando que tal advento, ao operar a passagem do mundo fechado - o cosmo ordenado - ao universo infinito, não 
tem seus efeitos restritos ao campo epistêmico-epistemológico. A incidência do advento da Ciência Moderna estende-se à fundação de uma nova articulação do real, que impõe exigências até então inéditas para o homem, de tal sorte que o lastro que sustenta seu lugar "em relação a si mesmo, em relação aos outros homens e em relação ao cosmo" (Costa-Moura \& Silva, 2012, p. 274) se vê vigorosamente impactado - de tal sorte que é o próprio laço social que se verá subvertido por tal impacto.

Assim, se por um lado, uma das vertentes precípuas da constituição da Ciência Moderna tem caráter aparentemente epistemológico - a matematização do real, tal como proposto por Galileu (1999, p.46), quando assevera que "[o grande livro da natureza] está escrito em língua matemática, os caracteres são triângulos, circunferências e outras figuras geométricas" -, por outro lado, Descartes (1999) põe em jogo que tal exigência não se restringe ao campo do conhecimento, o que produz profundas consequências no laço social. O primeiro passo de Descartes em sua busca pelas verdades inequívocas consiste na derrogação de toda e qualquer validade atribuível à verdade que pretendesse se sustentar na palavra, na autoridade ou, dito de outro modo, na enunciação. Deste modo, a palavra, que até então havia carregado um valor de verdade para o sujeito pela via da transmissão - ou da tradição - que havia carregado um lastro simbólico que permitia que ele se situasse no cosmo, se vê esvaziada, de modo que uma proposição vale tanto quanto seu contrário.

O advento da Ciência Moderna produz, portanto, uma transformação no laço social, na medida em que põe em xeque a autoridade sustentada na palavra, e que pode incidir como verdade para o sujeito - o que quer dizer, como afirma Lacan (1998b, p.889), que "da verdade, como causa, ela [a ciência] não quer-saber-nada", formulação que faz equivaler à da foraclusão. Neste passo, a lei simbólica - que encarna um paradoxo insolúvel se tomada em sua positividade, o que exige do sujeito um trabalho e um posicionamento em relação ao desejo (Lacan, 1999) - perde sua sustentação no escopo mais amplo da cultura, sendo deposta pela forma da lei positiva.

\section{A judicialização das relações familiares}

É assentada nesse enquadre que assistimos na contemporaneidade a uma espécie de judicialização da esfera privada, na qual a vítima aparece como figura proeminente. Esta é uma representação eminentemente jurídica - a rigor, oriunda do campo do direito penal, mais precisamente da criminologia. Nos países europeus assistimos ao surgimento de uma nova disciplina universitária, a vitimologia, tal 
é a relevância dada à figura da vítima nas sociedades contemporâneas fazendo com que se possa interrogar se estamos diante de um novo sujeito (Cacciali, 2005).

Este processo de judicialização da vida privada, sobretudo familiar, acarreta em sérias e, por vezes, graves consequências para as funções por esta concernidas, sobretudo as que dizem respeito aos lugares materno e paterno e à transmissão geracional, uma vez que o apelo dirigido à figura do juiz no sentido de arbitrar conflitos internos à ordem familiar parece convocar, em vão, a autoridade paterna, isto é, o antigo pátrio poder, destituído nas sociedades contemporâneas em prol da autoridade parental. Este fenômeno vem sendo amplamente observado pelos diferentes profissionais que atuam no campo jurídico, conforme assinala Levy:

O sujeito contemporâneo vem recorrendo cada vez mais ao poder judiciário enquanto instância normativa e reguladora, na busca de referências que the são externas e com as quais procura organizar seu mundo. (...) A Justiça, portanto, tem sido chamada a responder a questões que, até então, eram consideradas do âmbito privado. (Levy, 2003, p.35, grifo nosso).

A autora considera que o poder judiciário tem se prestado a substituir a figura paterna, numa formulação que corrobora a hipótese de Petitot (2005) segundo a qual o referido fenômeno é tributário da substituição da autoridade paterna pela parental, considerada mais equitativa e democrática, propriamente característica das sociedades contemporâneas. Contudo, segundo Petitot, esta substituição parece ter levado a uma espécie de degradação do lugar de autoridade, em nome dos supostos inalienáveis direitos da criança. Vale a pena registrar seu comentário a propósito desta relevante questão:

(...) a redução da noção de autoridade leva a considerar que nada mais será imposto à criança sem que ela consinta uma vez que esta é considerada, desde seu nascimento, como um sujeito (...) cuja vontade deve ser respeitada. Qualquer obrigação ou interdito impostos a uma criança serão considerados como um abuso de autoridade (...) é preciso não Ihes impor interditos, mas convencê-las, obter seu consentimento quanto aos limites necessários à sua vida pessoal e social. (Petitot, 2005, p.173).

Uma vez esvaziado o lugar da autoridade paterna na contemporaneidade, esta passará a ser atribuída ao juiz, aquele que enuncia os direitos e as proibições, numa indiferenciação entre a lei positiva e a lei simbólica, sendo esta última aquela que promove o 
advento da organização humana sob a forma de civilização (Petitot, 2005). Levy (2003) faz ainda uma importante distinção entre 'função' e 'papel', de acordo com a qual este último diria respeito a uma espécie de exercício de competência - ainda que parental - mais de acordo com a lógica empresarial, ao passo que a primeira é tributária de uma ordem propriamente simbólica, que demarca lugares e funções específicos, não intercambiáveis. De acordo com o modelo familiar contemporâneo, a família passaria a ser uma espécie de empresa a gerir, e não mais um locus constituído por lugares e funções pelos quais todos - e cada um - são responsáveis.

$\mathrm{Na}$ mesma direção, Costa-Moura (2004) problematiza algumas questões referentes ao Estatuto da Criança e do Adolescente (Lei № 8.069, de 13 de julho de 1990):

Com receio de que uma autoridade possa ser excessiva, corremos o risco de supor que a única forma de proteger a criança desses abusos é através de uma horizontalidade nas relações com ela. Porém, não é justamente essa horizontalidade que está em jogo nas situações de violência doméstica? Não é justamente esse apagamento relativo dos lugares e papéis que está implicado quando um adulto resolve ignorar ou distorcer suas responsabilidades frente à criança? No entanto, situados numa perspectiva que procura garantir para a criança um bem-estar assegurado como direito, não raro elimina-se a dissimetria de lugares que é essencial para o sujeito e que não é redutível à simetria, evocada na lei, entre o direito da criança ou do adolescente e o que disso resulta como dever para seus pais e responsáveis." (Costa-Moura, 2004, p. 67, grifo nosso).

A questão apontada pela autora é candente. Consideramos de extrema pertinência a observação de que a própria situação de violência pode ser compreendida como uma espécie de efeito colateral - tanto inesperado quanto indesejável - da abolição progressiva da dessimetria de lugares promovida pelo fenômeno de judicialização das relações familiares e/ou comunitárias. A horizontalidade nas relações familiares poderia inclusive propiciar o desregramento do sistema de parentesco presente na não submissão à interdição do incesto, observável em algumas situações de violência sexual contra crianças e adolescentes.

\section{A interdição do incesto como lei não escrita}

A interdição do incesto é uma proibição não escrita de caráter universal - lei simbólica - que funda a ordem social, para além da 
natureza onde vigora a 'lei' do mais forte; é o fundamento da cultura e do sujeito, isto é, trata-se de um elemento intrínseco e constitutivo da ordem humana, e segundo Freud (1974a) marca a passagem da natureza à cultura. Portanto, o homem em estado natural caracteriza-se por um gozo ao qual não se impõe qualquer tipo de limite, de tabu, e que se sustenta unicamente pelo primado da força, em oposição à incidência simbólica da lei. Consequentemente, não se estabelece a dimensão da diferença, da alteridade; pois qualquer modificação dos ocupantes dos lugares do grupo - por exemplo, a derrota, numa luta, do macho mais forte para outro ainda mais forte, com sua consequente substituição - não engendra qualquer tipo de consequência para sua estrutura. Neste sentido, é mesmo impreciso chamar o macho mais forte de "pai" e sua progênie de "filhos"; pois se, num segundo momento, um de seus descendentes viesse a destroná-lo, passaria a ocupar o lugar que fora seu numa continuidade imediata, sem que isso viesse a ter qualquer tipo de efeito, de reordenação nessa estrutura. A descrição freudiana do estado natural do homem, portanto, não comporta qualquer tipo de diferença geracional - e nem sexual, à medida que a dimensão do desejo não se articula nessa estrutura onde a batalha de vida e morte orbita a pugna pela senhoria do gozo.

Nas formulações de Lévi-Strauss encontramos proposição semelhante à freudiana:

A proibição do incesto (...) constitui o passo fundamental graças ao qual, pelo qual, mas, sobretudo no qual se realiza a passagem da natureza à cultura. (...) O papel primordial da cultura está em garantir a existência do grupo como grupo, e portanto em substituir, nesse domínio como em todos os outros, a organização ao acaso. A proibição do incesto constitui uma certa forma - e mesmo formas muito diversas - de intervenção. Mas, antes de tudo, é intervenção, ou ainda, é a Intervenção (Lévi-Strauss, 2003, p. 72).

Desse modo, a figura paterna representa não apenas o genitor, mas uma função social; portanto, a cada vez e em cada família, 'pai' é aquele que encarna a ordem da lei assegurando a sucessão das gerações bem como a transmissão do nome. "Pai" é ainda aquele que renuncia a tomar seu/sua filho(a) como objeto sexual. Se um indivíduo vem a transgredir a lei cujo estatuto simbólico a função paterna assegura, é a própria ordem cultural que se encontra, por conseguinte, em risco.

Sabe-se que o incesto, para além da subversão dos laços consanguíneos, implica em uma subversão do próprio laço social, uma vez que já não é mais possível nomear apropriadamente o grau de parentesco, e, por conseguinte, distinguir os laços que unem os 
membros de uma mesma família. Quanto a este ponto, Rosenfield assinala:

[O incesto] não representa [apenas] uma transgressão pontual no registro da sexualidade, mas o desregramento de todo o sistema de parentesco e, consequentemente, da sociabilidade. Os nomes e graus de parentesco não significam mais nada quando um 'pai' é ao mesmo tempo irmão de seus filhos e filho de sua esposa [como no caso da tragédia grega Édipo Rei]. Essa confusão linguística repercute sobre as representações do tempo e do espaço, pois as gerações anterior e posterior misturam-se inextrincavelmente, disputando estatutos e lugares simbólicos (Rosenfield, 2002, p. 67, grifo nosso).

Assim, evidencia-se que a transgressão do tabu do incesto não caracteriza unicamente um fenômeno de ordem privada, mas também pública, já que ao subverter os estatutos e lugares simbólicos que asseguram o pertencimento de cada sujeito à cadeia geracional põe em risco a própria ordem cultural. Vale dizer, zelar pela manutenção da própria ordem simbólica que constitui o laço social implica em fazer valer a dessimetria de lugares, possibilitando com que cada sujeito venha a assumir o lugar que lhe cabe na linhagem. A horizontalidade nas relações entre os membros de uma mesma família abole a dessimetria cujo estatuto simbólico lhe é intrínseco e constitutivo, podendo acarretar na sua própria disrupção. No entender de Garapon,

Nenhuma coletividade é possível sem sistemas simbólicos, como a linguagem ou o parentesco, que têm em comum o fato de manter posições auto-excludentes. (...) A criança não pode trocar de posição com seus pais, essa relação não é simétrica. O direito é o guardião dessa ordem simbólica, sem a qual nenhuma troca seria possível. (...) Não existe sujeito de direito sem função simbólica, quer dizer, sem uma palavra comum que o coloque em perspectiva. (Garapon, 2001, p.202, grifos nossos)

Seria preciso levar em conta a advertência do magistrado: desprovido de função simbólica não há lugar para o sujeito, nem mesmo para o sujeito de direito cujas prerrogativas a lei positiva visa garantir.

\section{A vítima, o sujeito}

É neste contexto das relações familiares caracterizado pela invasão do campo do direito sobre a esfera privada que emerge a figura 
privilegiada da vítima. De acordo com Cacciali, esta é a representação social e o suporte privilegiado do sujeito excluído pelo discurso da ciência, cujo caráter universalizante pretende abolir a dimensão do singular. Nesse sentido, a queixa seria o modo de expressão por excelência deste sujeito excluído, sob a forma de sua vitimização por parte de outro - quer se trate de outro indivíduo ou ainda de uma instituição social (Cacciali, 2005, p.156).

Segundo este autor, a posição de vítima é assumida por um sujeito que demanda reparação. Mas esta é uma via que resulta em um impasse, do ponto de vista da psicanálise. O próprio autor adverte:

O sujeito que é privado de um objeto por um evento exterior do qual ele é a vítima não será um sujeito do desejo; aquilo que será privilegiado, será a demanda. (...) A vítima, se esta [figura] constituir a totalidade de sua subjetividade, irá se engajar na demanda ao preço da exclusão do desejo. (Cacciali, 2005, pp.164-165, grifo nosso).

Sabemos que uma demanda de reparação pode se estender ao infinito sem que jamais possa ser satisfeita. Um sujeito fixado na posição de vítima estará fadado a degradar a dimensão do desejo à demanda, que é sempre demanda de amor e de reconhecimento, ao preço da elisão do desejo. Ou seja, na posição de vítima o sujeito recua e, demitindo-se de sua parcela de responsabilidade, passa a outorgar a outro a responsabilidade sobre sua vida, cabendo a este dizer qual é o seu - do sujeito - lugar.

As considerações que se seguem se desenvolveram a partir de questões que atravessaram a prática institucional no campo da assistência social de um dos autores do presente artigo, a partir de sua inserção profissional ${ }^{2}$, cuja interface com o campo jurídico é assaz estreita. Na qualidade de ditos 'especialistas' - no caso, psicólogo - estes são solicitados a realizar uma avaliação de caráter técnico diante de situações em que há uma suspeita de violência sexual contra crianças e adolescentes, sendo que esta solicitação parte, em sua maioria, de instituições e órgãos que compõem o Sistema de Garantia de Direitos ${ }^{3}$, entre outras demandas.

Esta condição foi juridicamente tornada possível à medida que crianças e adolescentes passaram a ser reconhecidos como sujeitos de direitos pela Convenção Internacional dos Direitos da Criança e do Adolescente em 1989 e, no ano seguinte, através da promulgação da Lei no 8.069 de 13 de julho de 1990 (mais conhecida como Estatuto da Criança e do Adolescente/ECA).

A partir do segundo semestre de 2007 uma nova metodologia foi adotada com relação ao acompanhamento realizado no então denominado SECABEXS (Serviço de Combate ao Abuso e Exploração Sexual de Crianças e Adolescentes) ${ }^{4}$ em substituição à chamada 
Entrevista de Revelação, sendo esta técnica preferencialmente utilizada, até aquela data. Esta é oriunda de países anglo-saxões, sobretudo dos Estados Unidos da América, sendo de orientação marcadamente positivista e pragmática, cujo peso da avaliação recai exclusivamente sobre a palavra da criança e/ou do adolescente na determinação do fato da violência. Nos casos de violência intrafamiliar, via de regra, o autor da agressão não era escutado, uma vez que era considerado o 'suspeito' do ato supostamente criminoso. Esta técnica (Entrevista de Revelação) não era utilizada a título de diretriz metodológica institucional, mas apenas em decorrência do fato de que a maior parte dos psicólogos, que então atuavam em um dos dispositivos da Proteção Social Especial de Média Complexidade, era oriunda de uma organização não governamental pioneira no atendimento aos casos de violência sexual infanto-juvenil, na qual a referida técnica era adotada.

A nova proposta de atendimento aos casos de violência sexual infanto-juvenil, progressivamente implementada a partir de maio de 2007, teve como gestora a Subsecretaria de Proteção Social Especial da Secretaria Municipal de Assistência Social da Cidade do Rio de Janeiro. O critério de avaliação passou a considerar a situação de violência e não mais privilegiou a problemática concernente a esta como um fato a ser determinado e/ou averiguado no âmbito da Proteção Social de Média Complexidade, cujos dispositivos de atendimento são os Centros de Referência Especializados de Assistência Social/CREAS ${ }^{5}$.

De acordo com esta nova abordagem das situações de violação de direitos de crianças e adolescentes, declinada sob a forma de violência sexual, a fala da criança e/ou do adolescente passou a constituir um dos elementos do acompanhamento psicológico e social, além da avaliação da dinâmica familiar através do acompanhamento parental e/ou familiar. Nos casos de violência sexual supostamente ocorrida no âmbito familiar o(a) (também) suposto(a) autor(a) da agressão passou a ser convidado a comparecer ao serviço, levandose em conta o lugar que este(a) ocupa frente à criança e/ou ao adolescente - pai, mãe, irmã(o), avô/avó, tio(a), primo(a) - e não como 'suspeito(a)'.

Com isso, visou-se propiciar a possibilidade de ressignificação da situação de violência por parte dos atores nela envolvidos, assim como o fortalecimento dos vínculos familiares e comunitários, de acordo com o princípio de matricialidade sócio-familiar estabelecido pelo Sistema Único de Assistência Social/SUAS.

$\mathrm{Na}$ prática do psicanalista inserido nos dispositivos institucionais da Proteção Social de Média Complexidade, este se vê chamado a intervir por solicitação de diferentes instâncias para que realize uma avaliação psicológica nos casos de suspeita de violência sexual de crianças e adolescentes. Parece ser oportuno refletir sobre a 
demanda que lhe é dirigida, assim como sobre a especificidade de sua função, isto é, sobre a posição que lhe cabe sustentar.

Conforme destacado anteriormente, seu papel não é o de proceder a uma espécie de investigação técnica ou especializada do objeto da queixa e/ou da denúncia, ao cabo da qual haveria um culpado a apontar. Tampouco implica em qualquer espécie de "revelação", termo que denota o ato ou efeito de revelar - verbo que, por sua vez, possui uma carga semântica extensa, significando tanto descobrir, desvelar, fazer, conhecer, declarar, divulgar, denotar, mostrar como também delatar, denunciar. No decorrer do atendimento aos casos de violência sexual de crianças e adolescentes encaminhados aos CREAS tantas coisas são reveladas, para além da suposta violência!

Qual é, então, a especificidade de sua função no acompanhamento de um caso em que há a suspeita de que uma criança ou um adolescente foram tomados como objeto sexual por parte de um adulto, sem o seu consentimento? Certamente o relato da criança ou do adolescente é um elemento relevante, mas não o único a considerar. Uma criança ou um adolescente podem fazer da fala de um adulto - especialmente em se tratando de seus pais - a sua própria fala; podem ainda fantasiar uma situação sem que ao leigo seja possível distinguir uma fantasia carregada de desejo de uma ocorrência supostamente real, uma vez que, desde Freud e com Lacan, a própria realidade humana tem uma estrutura de ficção.

Muito cedo em sua prática clínica Freud (1977) se deparou, a propósito do fenômeno histérico, com o fato de que a força real do traumatismo - no caso, o relato de uma cena de sedução, que pouco difere daquilo que atualmente é denominado 'abuso sexual' - reside no fato de que a fantasia é a realidade do sujeito, fazendo com que ele abandonasse a teoria do trauma em favor da fantasia de sedução. Assim, fez "(...) a descoberta comprovada de que, no inconsciente, não há indicação de realidade, de modo que não se consegue distinguir entre a verdade e a imaginação que está catexizada [investida/besetz] de afeto" 6 (Freud, 1977, p. 351, grifo nosso).

Desse modo, quando uma criança ou adolescente relata um episódio no qual supostamente teria sido 'abusada/o' sexualmente, para além de averiguar se esta fala corresponde à verdade (dos fatos), trata-se de reconhecer o fato de que há ali uma verdade. No entender de Lacan, "É que a uma nova verdade não podemos contentar-nos em dar lugar, porque é de assumir nosso lugar nela que se trata" (Lacan, 1998a, p.525). O sujeito está sempre implicado naquilo mesmo de que ele se queixa, vale dizer, está representado em sua fala.

Conforme Petitot assinala de forma aguda, as palavras de uma criança, "Como as de qualquer um de nós, são infiltradas de imaginário e de reconstrução" (Petitot, 2005, p.179). A memória não caracteriza uma função de registro (e sua recuperação posterior); ao contrário, é constituída fragmentariamente através do 
remanejamento, a posteriori, de restos de imagens, de palavras, de experiências que são sempre as de um sujeito - e não em si mesmas. Assim, o quê privilegiar na escuta dos casos em que o que está em causa é (a princípio) uma suposta violência sexual contra uma criança ou um adolescente? O conteúdo do que é dito ou o fato de que alguém (e quem) - o diz? Quando um sujeito toma a palavra - ao, por exemplo, narrar um acontecimento -, seria no mínimo ingênuo pensar que há um sujeito previamente constituído que relata um fato objetivo; antes, um sujeito se constitui no e pelo próprio movimento de dizer, de se endereçar a outro enquanto testemunha da sua fala. Cabe ainda assinalar que um sujeito, ao dizer, diz sempre mais (ou menos) do que sabe ou do que pretendia dizer, ou seja, não é contemporâneo a si mesmo, mas estruturalmente dividido.

Cumpre pôr em relevo a observação de Lacan de que

A história não é o passado. A história é o passado na medida em que é historiado no presente - historiado no presente porque foi vivido no passado. (...) 0 fato de que o sujeito revive, rememora, no sentido intuitivo da palavra, os eventos formadores da sua existência, não é, em si mesmo, tão importante. O que conta é o que ele disso reconstrói. (...) Afinal de contas, o de que se trata é menos lembrar do que reescrever a história (Lacan, 1986, pp.21-23, grifo nosso).

Vê-se que a ênfase não é posta sobre o vivido, mas sobre aquilo que do vivido pode ser dito, colocado em palavras, isto é, tornar-se o discurso de um sujeito que, enquanto tal, encontra-se sempre implicado no que diz. Ao contar, um sujeito se conta, ou seja, fala de si, inclui-se naquilo que diz pelo próprio ato de dizer.

Sabemos que não há sujeito prévio às marcas que o constituem, uma vez que este não se confunde com a unidade biológica denominada organismo; um sujeito é o resultado das marcas de sua história, isto é, daquilo que ele faz (ou consente em fazer) com aquilo que the acontece. E esta, como vimos, é repertoriada - e propriamente constituída - no presente, sendo, portanto, feita de palavras - assim como as lembranças.

Assim, não é possível desconhecer que se a ênfase não é posta sobre o (supostamente) vivido, mas, sim, naquilo que um sujeito constitui como verdade no relato que faz, o que pode se tornar verdadeiramente traumático é não tanto o evento em si mesmo, mas o lugar e o peso que se dá a ele, conforme esclarece Melman (2005). Este também é o entendimento de Gonçalves (2004) que, ao citar um relevante estudo a propósito do impacto da violência sobre uma criança ou um adolescente, afirma que este (o impacto) depende não do fato em si, mas de um conjunto de circunstâncias, quais sejam: 
a. Da própria natureza da violência (...);

b. Das características individuais da criança, que preexistem à violência;

c. Da natureza da relação entre agressor e vítima (...);

d. Da resposta social à violência sofrida (...);

e. Do apoio que a criança recebe por parte dos outros significativos, em especial no núcleo familiar (...);

(...) Em suma, a reação da criança depende não só da violência per si mas também, e em grande medida, do processo que tem curso após o evento violento. (Emery \& Laumann-Billings, 1998, citado por Gonçalves, 2004, pp. 289-290, grifo nosso).

Desse modo, a posição de quem escuta a queixa que the é endereçada será decisiva para a própria constituição (ou não) do trauma; logo, de sua suposta vítima. Não obstante, é possível dialetizar os efeitos da violência resgatando, através da escuta dos sujeitos nela envolvidos, a circulação da palavra e os lugares simbólicos, promovendo a ressignificação da situação de violência e possibilitando que os laços afetivos e sociais, esgarçados pela própria situação de violência, possam ser retecidos. Fora desta perspectiva restará ao sujeito o lugar de vítima, cuja demanda de reparação jamais poderá vir a ser plenamente satisfeita em virtude do próprio estatuto desta posição fixada. Por conseguinte, condenada à queixa.

O psicanalista tem a oferecer a sua escuta advertida, sem fazer desta um juízo sobre o que Ihe é dito. Advertida, sobretudo, de que o malestar é inerente à condição humana, a título de preço a pagar pela constituição do sujeito na cultura. Para Freud, são três as fontes do mal-estar, a partir das quais o sofrimento acossa o sujeito: o próprio corpo, o mundo externo e a relação com os outros homens - sendo que esta última é a que ele considera a mais penosa (Freud, 1974b, p.95, grifo nosso). Vê-se que a promessa de felicidade não está incluída na aventura humana, demasiado humana, de nossa existência. Talvez seja uma das razões pelas quais o fundador da psicanálise tenha sido considerado um trágico na era da ciência.

Retomando a noção de 'protagonismo' estabelecida pelo Sistema Único de Assistência Social/SUAS, cabe destacar sua origem na Grécia Antiga, com o surgimento da tragédia no século $V$ a.C. Até então, o destino do homem era ditado pelos deuses e proclamado pelo canto do aedo. Com o advento do teatro ático o homem é problematizado em relação à sua ação, pela qual é plenamente responsável, a despeito do vaticínio dos deuses (Vorsatz, 2013) ${ }^{7}$. Na figura do primeiro ator ou protagonista, ele toma a palavra pela primeira vez e, diante da polis reunida, responsabiliza-se por sua sina, ainda que trágica. Protagonizar é, desde então, falar em nome próprio e tomar em mãos o seu destino. 
Ao psicanalista cabe, através da especificidade de sua escuta, possibilitar que os sujeitos concernidos por uma experiência de violência sexual - tanto a criança e o adolescente como, no caso da violência intrafamiliar, seus pais e/ou familiares nela envolvidos possam tomar a palavra e, ao fazê-lo, situar-se como sujeitos de sua história, e não como meras vítimas dos acontecimentos - ou ainda seus algozes. Trata-se, neste sentido, de uma aposta na efetividade da palavra, em especial na aposta de um recolhimento da palavra por uma escuta. Vale dizer, apostar na escuta enquanto um dispositivo clínico ou, inversa e reciprocamente, na clínica como dispositivo de escuta. Está em jogo aqui a radicalidade da posição de Lacan (1992) ao subverter a noção comum de clínica como terapêutica, ao estabelecer, dentre os quatro discursos, aquele que é o do psicanalista. A clínica psicanalítica, pois, se constitui numa relação específica com a linguagem, com os termos que constituem a estrutura da linguagem, e na resposta que se pode dar ao endereçamento veiculado àquele que escuta - resposta esta que se dirige não à pacificação da demanda, mas, mesmo que minimamente, ao sujeito que se coloca em ato na enunciação.

Pensando-se a clínica pela via discursiva, trata-se, sobretudo, de colocar a especificidade da escuta psicanalítica a serviço da polis, lembrando, com Freud (1976), de que não há distinção estrutural entre psicologia individual e social: dar lugar ao sujeito tem consequências sobre o social, mais ainda, constitui um determinado laço social.

Se não é possível reparar a vida - o tempo não recua nem para ainda assim é possível elaborar o vivido, ressignificar as marcas e (re)escrever a própria história.

\section{Considerações finais}

As dificuldades encontradas pelo psicanalista inserido no campo da Assistência Social e incumbido da escuta e do acompanhamento às situações de violação de direitos de crianças e adolescentes concernentes à violência sexual são, primordialmente, de duas ordens: internas e externas ao serviço em que atuam. As principais dificuldades internas são: 1) certa indistinção em relação a demanda que lhe é dirigida institucionalmente. Apesar de que as categorias profissionais sejam perfeitamente distinguidas pelos gestores, a demanda, no que tange o acompanhamento às situações de violação de direitos no âmbito da Proteção Social Especial de Média Complexidade é, muitas vezes, indistintamente endereçada seja ao psicólogo, seja ao assistente social, de modo intercambiável; 2) a inexistência de supervisão regular em relação à atuação dos psicólogos no âmbito da PSE, a partir do que a complexidade dos 
casos pudesse ser problematizada, bem como as dificuldades inerentes a sua condução, permitindo que experiências singulares e formadoras pudessem ser compartilhadas entre os profissionais. ${ }^{8}$

Há ainda dificuldades de ordem externa ao serviço, de caráter socioassistencial, que costumam estar relacionadas à demanda endereçada pelos demais atores que compõem o Eixo 1 do Sistema de Garantia de Direitos, sobretudo pelos órgãos de Defesa do Direitos Humanos. De acordo com a Resolução № 133 do CONANDA, são eles: Judiciais, Público-Ministeriais, Defensorias Públicas e Serviços de Assessoramento J urídico ou de Assistência Judiciária, Advocacia Geral da União e Procuradorias Gerais dos Estados, Polícia Civil, Polícia Militar, Conselhos Tutelares, Ouvidorias e Entidades Sociais de defesa dos direitos. Via de regra, a demanda por parte desses órgãos é a de esclarecimento quanto suposta à situação de violência sexual contra crianças e adolescentes - se esta ocorreu, em que circunstâncias e quem teria sido o(a) autor(a) da violência.

Por vezes, parece haver um desconhecimento quanto ao acompanhamento desses casos no âmbito da Proteção Social Especial de Média Complexidade - muitas vezes, também por parte dos próprios profissionais que nela atuam -, concomitante a uma expectativa de que a situação seja 'esclarecida' de modo a que os órgãos de Defesa e Responsabilização venham a ser municiados das informações de que necessitam para, se for o caso, agir. Se assim fosse, a especificidade da escuta advertida se veria reduzida a uma atividade de cunho pericial, caracterizando sua atuação como uma espécie de braço técnico da lei. Nada mais distante de sua função precípua, qual seja, a de acolher, escutando sem julgar, e sem nenhum propósito alheio ao próprio atendimento.

Entendemos que atender a este tipo de demanda sem problematizála desde sua especificidade no campo da Política Nacional de Assistência Social é um risco permanentemente à espreita. E, nesse sentido, a supervisão institucional caracterizaria o fórum privilegiado para tratar das questões concernentes ao atendimento das situações de violência sexual contra crianças e adolescentes no âmbito da PSE, situações por demais complexas e cujas consequências podem ser desastrosas, conforme o encaminhamento dado a cada caso.

O próprio Ministério de Desenvolvimento Social e Combate à Fome preconiza, em relação aos documentos resultantes de acompanhamento psicológico e social realizado no âmbito da Proteção Social Especial: "Os relatórios do CREAS não devem se confundir com a elaboração de 'laudos periciais', relatórios ou outros documentos com finalidade investigativa que constituem atribuição das equipes interprofissionais dos órgãos do sistema de Defesa e Responsabilização." (MDS, 2011). 
Tomando a problemática por outro viés, destacamos o alerta de Calligaris (1991) para o fato de que vivemos, na contemporaneidade, sob a paixão ${ }^{9}$ da instrumentalidade:

(...) O que (se) chama o triunfo da técnica, da instrumentalidade, só é triunfo na medida em que os homens mesmos funcionem como parte integrante desta técnica, quero dizer, funcionem como instrumentos. Em outras palavras, onde (se) fala de efeito da técnica, do desenvolvimento da técnica, acho que poderíamos falar do efeito do interesse e da paixão humana em sair do sofrimento neurótico banal, alienando a própria subjetividade, ou melhor reduzindo a própria subjetividade a uma instrumentalidade." (Calligaris, 1991, p.110, grifo do original).

O sujeito se aliena, apaga-se enquanto sujeito ao se fazer mero instrumento de uma técnica, vale dizer, da aplicação estrita de um conjunto de conhecimentos, que como tal é sempre acéfalo. Assim, enquanto "especialistas" nas questões relativas à violência sexual contra crianças e adolescentes, um dos riscos implicados nessa prática seria alienar a nossa escuta transformando-a em um mero instrumento de aplicação da lei positiva, ao invés de procurar garantir a possibilidade sempre renovada de que um sujeito possa emergir ao se responsabilizar por sua história, nela se implicando.

Trazemos estes elementos à reflexão no intuito de que possamos, ao problematizar as especificidades e os impasses intrínsecos a este campo de trabalho, evitar a tentação de nos tornarmos instrumentos de uma técnica que, por não dar lugar ao sujeito, condena-o a uma alienação ao estatuto de "vítima", o que pode vir a ser mais danoso do que a experiência que lhe coube, ainda que penosamente, viver.

"Que se diga fica esquecido detrás do que se diz no que se ouve", afirma Lacan (1982, p.26); logo, a importância encontra-se menos no conteúdo do que é dito do que no fato de que um sujeito diz, e ao dizer, constitui, em ato e a cada vez, a sua história, permanecendo aberta a possibilidade de dela se tornar protagonista.

De resto, estamos suficientemente advertidos por Freud (1975, p.282) de que governar, educar e curar constituem tarefas impossíveis, uma vez que sabemos de antemão que seus resultados serão necessariamente parciais, na contramão dos ideais. Tarefa decerto impossível, a nossa, mas não impraticável: eis o desafio em relação ao qual nos vemos permanentemente convocados. 


\section{Referências}

Brasil (1990). Lei № 8.069 de 13 de julho de 1990. Estatuto da criança e do adolescente. Presidência da República. Brasília: Diário Oficial da União, 16 de julho de 1990.

Cacciali, J. -L. (2005). La victime: un nouveau sujet. In Lebrun, J. -P. (org.). Les désarrois nouveaux du sujet - prolongements théorico-cliniques au monde sans limite (pp. 153-168). Paris: Éres.

Calligaris, C. (1991). A sedução totalitária. Clínica do Social. São Paulo: Escuta, pp. 105-118.

Conselho Nacional de Assistência Social/CNAS (2004). Resolução № 145, de 15 de outubro de 2004. Política Nacional de Assistência Social/PNAS.

Conselho Nacional de Assistência Social/CNAS (2005). Resolução № 130, de 15 de julho de 2005. Norma Operacional Básica do Sistema Único de Assistência Social/NOB-SUAS.

Conselho Nacional de Assistência Social/CNAS (2005). Resolução № 269, de 13 de dezembro de 2006. Norma Operacional Básica de Recursos Humanos do Sistema único de Assistência Social/NOBRH-SUAS.

Conselho Nacional de Assistência Social/CNAS (2009). Resolução № 109, de 11 de novembro de 2009. Tipificação Nacional de Serviços Socioassistenciais.

Conselho Nacional dos Direitos das Crianças e dos Adolescentes/CONANDA (2006). Resolução 113, de 20 de abril de 2006. Sistema de Garantia de Direitos de Crianças e Adolescentes.

Costa-Moura, F. (2004). Contextualizando a relação com a lei avanços e dificuldades a partir do ECA. In Gryner, S. (org.). A violência começa quando a palavra perde o valor - uma experiência de supervisão com profissionais de saúde na abordagem de situações de violência doméstica. (pp. 65-73). Rio de Janeiro: NAV.

Costa-Moura, F. \& Silva, M. E. A. (2012). Do mundo fechado...ao desuniverso do discurso. Santos, T. C., Martello, A. \& Santiago, J. (orgs.) De que real se trata na clínica psicanalítica? (pp. 271294). Rio de Janeiro: Companhia de Freud.

Descartes, R. (1999). Discurso do método. In Os pensadores. (p. 33100). São Paulo: Nova Cultural. (Obra originalmente publicada em 1637).

Freud, S. (1974a). Totem e tabu. In Edição Standard Brasileira das Obras Completas de Sigmund Freud. (Vol. XIII, pp. 13-191). Rio de Janeiro: Imago. (Obra originalmente publicada em 1913).

Freud, S. (1974b). O mal-estar na civilização. In Edição Standard Brasileira das Obras Completas de Sigmund Freud. (Vol. XXI, 
pp. 75-171). Rio de Janeiro: Imago, 1974. (Obra originalmente publicada em 1930[1929]).

Freud, S. (1975). Análise terminável e interminável. In Edição Standard Brasileira das Obras Completas de Sigmund Freud. (Vol. XXIII, pp. 239-287). Rio de Janeiro: Imago. (Obra originalmente publicada em 1937).

Freud, S. (1976). Psicologia das massas e análise do eu. In Edição Standard Brasileira das Obras Completas de Sigmund Freud. (Vol. XVIII, pp. 89-179). Rio de Janeiro: Imago. (Obra originalmente publicada em 1921).

Freud, S. (1977). Carta 69. In Edição Standard Brasileira das Obras Completas de Sigmund Freud. (Vol. I, pp. 350-352). Rio de Janeiro: I mago. (Obra originalmente publicada em 1897).

Galilei, G. (1999). O ensaiador. In Os pensadores. (pp. 17-256). São Paulo: Nova Cultural. (Obra originalmente publicada em 1623).

Garapon, A. (2001). O juiz e a democracia: o guardião das promessas. Rio de Janeiro: Revan.

Gonçalves, H. S. (2004). Violência contra a criança e o adolescente. In Brandão, E. \& Signorini, H. G. (org.) Psicologia Jurídica no Brasil (pp. 277-307). Rio de Janeiro: Nau.

Koyré, A. (1982). Galileu e a revolução científica do século XVII. Estudos de história do pensamento científico (pp. 181-196). Rio de Janeiro: Forense Universitária, 1982. (Obra original publicada em 1955).

Lacan, J. (1982). O seminário, livro 20: mais, ainda. Rio de Janeiro: Jorge Zahar Editor. (Seminário proferido em 1972-1973).

Lacan, J. (1986). O seminário, livro 1: os escritos técnicos de Freud. Rio de Janeiro, Jorge Zahar Editor. (Seminário proferido em 1953-1954).

Lacan, J. (1992) O seminário, livro 17: o avesso da psicanálise. Rio de Janeiro: Zahar, 1992. (Seminário proferido em 1969-1970).

Lacan, J. (1998a). A instância da letra no inconsciente ou a razão desde Freud. In Escritos. (pp. 496-533). Rio de Janeiro: Jorge Zahar Editor. (Obra originalmente publicada em 1966[1957]).

Lacan, J. (1998b). A ciência e a verdade. In Escritos. (pp. 869-892). Rio de Janeiro: Zahar. (Obra originalmente publicada em 1966[1965])

Lacan, J. (1999). O seminário, livro 5: as formações do inconsciente. Rio de Janeiro, Jorge Zahar Editor. (Seminário proferido em 1957-1958).

Lacan, J. (2005). O seminário, livro 10: a angústia. Rio de Janeiro, J orge Zahar Editor. (Seminário proferido em 1962-1963).

Lévi-Strauss, C. (2003). As estruturas elementares de parentesco. Petrópolis: Vozes. (Obra original publicada em 1947). 
Levy, L. (2003). Quero falar com Dr. Siro: o poder judiciário e a função paterna. In Féres-Carneiro, T. (org.). Arranjos e demandas contemporâneas. (pp.35-45). São Paulo: Loyola.

Melman, C. (2005). A propósito do incesto. In Melman, C. Será que podemos dizer, com Lacan, que a mulher é o sintoma do homem? (pp. 135-155). Rio de Janeiro: Tempo Freudiano Associação Psicanalítica.

Ministério do Desenvolvimento e Combate à Fome \& Secretaria Nacional de Assistência Social (2011). Orientações técnicas: Centro de Referência Especializado de Assistência Social. Brasília.

Petitot, F. (2005). On bat un enfant: a propos de la maltraitance. In Lebrun, Jean-Pierre (org.) Les désarrois nouveaux du sujet prolongements théorico-cliniques au Monde sans limite (pp. 169-182). Paris: Éres.

Rosenfield, K. H. (2002). Sófocles \& Antígona. Rio de Janeiro: Jorge Zahar Editor.

Vorsatz, I. (2013). Antígona e a ética trágica da psicanálise. Rio de Janeiro: Jorge Zahar Editor/FAPERJ .

\section{Endereço para correspondência \\ Ingrid Vorsatz}

Universidade do Estado do Rio de Janeiro - UERJ

Rua São Francisco Xavier, 524, Pavilhão J oão Lyra Filho, 10ㅇ andar, sala 10.006 Bloco B, Maracanã, CEP 20550-013, Rio de Janeiro - RJ, Brasil

Endereço eletrônico: ingrid.vorsatz@uerj.br

\section{Marcos Eichler de Almeida Silva}

Universidade do Estado do Rio de Janeiro - UERJ

Rua São Francisco Xavier, 524, Pavilhão J oão Lyra Filho, 10 andar, sala 10.006 Bloco B, Maracanã, CEP 20550-013, Rio de Janeiro - RJ, Brasil

Endereço eletrônico: marcoseichler@gmail.com

Recebido em: 08/05/2015

Aceito em: 28/07/2016

\section{Notas}

* Professora Adjunta do Instituto de Psicologia da Universidade do Estado do Rio de Janeiro. Doutora em Teoria Psicanalítica pela Universidade Federal do Rio de Janeiro. Coordenadora do Curso de Especialização em Psicologia Clínica Institucional - Modalidade Residência Hospitalar - IP-UERJ. Coordenadora da Comissão de Residência Multiprofissional e em Área Profissional de Saúde/COREMUUERJ .

** Professor Adjunto do Instituto de Psicologia da Universidade do Estado do Rio de J aneiro. Doutor em Teoria Psicanalítica pela Universidade Federal do Rio de Janeiro.

1. O presente artigo constitui uma versão revista e ampliada de um documento de trabalho de um dos autores, de circulação interna, divulgado exclusivamente no âmbito da Subsecretaria de Proteção Social Especial/Secretaria de Assistência Social da Prefeitura da Cidade do Rio de Janeiro no ano de 2007. 
2. Esta se deu entre os anos de 2007 e 2012, no âmbito da Secretaria Municipal de Assistência Social da Prefeitura da Cidade do Rio de Janeiro, quando da atuação profissional no âmbito de Proteção Social Especial de Média Complexidade.

3. O Sistema de Garantia de Direitos da Criança e do Adolescente constitui-se na articulação e integração das instâncias públicas governamentais e da sociedade civil, na aplicação de instrumentos normativos e no funcionamento dos mecanismos de promoção, defesa e controle para efetivação dos direitos da criança e do adolescente nos níveis Federal, Estadual, Distrital e Municipal. Seus eixos estratégicos são: 1. Defesa dos direitos humanos; 2. Promoção dos direitos humanos; 3. Controle da efetivação dos direitos humanos. (Resolução № 133, Conselho Nacional dos Direitos das Crianças e dos Adolescentes/CONANDA, 2006). Estes três eixos estruturantes do SGD, embora sejam, complementares, não se superpõem. Tampouco se encontram subordinados hierarquicamente uns a outros, mas concorrem, conjuntamente, para a garantia dos direitos humanos de crianças e adolescentes. Conforme o Artigo 14 da Resolução № 133, o eixo da Promoção dos Direitos Humanos se operacionaliza através do desenvolvimento de uma política de atendimento aos direitos de crianças e de adolescentes, prevista no Artigo 86 do Estatuto da Criança e do Adolescente. Já o artigo 15o da referida Resolução dispõe que a política de atendimento dos direitos de crianças e adolescentes operacionaliza-se através de três tipos de programas, serviços e ações públicas, dentre os quais os serviços e programas das políticas públicas, especialmente das políticas sociais, afeitos aos fins da política de atendimento dos direitos humanos de crianças e adolescentes. As situações de violação dos direitos de crianças e adolescentes são encaminhadas aos Centros de Referência Especializados de Assistência Social, para acompanhamento psicológico e social.

4. Este serviço foi posteriormente subsumido ao Serviço de Proteção e Atendimento Especializado a Famílias e Indivíduos/PAEFI, de acordo com a Tipificação Nacional de Serviços Socioassistenciais (Resolução № 109, de 11 de novembro de 2009).

5. A implementação se deu inicialmente nos CREAS Maria Lina de Castro Lima (2 2 a Coordenadoria de Desenvolvimento Social), localizado na Zona Sul, e Padre Guilherme Decaminada (10 ${ }^{\text {a }}$ Coordenadoria de Desenvolvimento Social), localizado na Zona Oeste da cidade do Rio de Janeiro. A estes se seguiram, ainda no ano de 2007, os CREAS Nelson Carneiro (4a CAS), Professora Márcia Lopes (5a aAS) e Dina Sfat (8a CAS). Atualmente o município do Rio de Janeiro dispõe de quatorze CREAS.

6. Lembrando que afeto (Affekt) é o que afeta o sujeito. De acordo com Lacan (1962-63/2005), o afeto por excelência é a angústia.

7. Surge, aí, a problematização ética em sua dimensão trágica, que Lacan destacou ao tratar da especificidade intrínseca à ética da psicanálise.

8. Entre julho de 2012 e janeiro de 2013 foi instituída a supervisão dos psicólogos que atuavam nos dispositivos da PSE de Média Complexidade (CREAS e Centros POP) pela então Direção da Proteção Social de Média Complexidade da Subsecretaria de Proteção Social Especial da Secretaria de Assistência Social da Prefeitura do Rio de Janeiro. Em maio de 2012, a gestora nos solicitou um projeto de supervisão, que teve início em julho daquele ano. Uma vez ao mês os psicólogos que atuavam no âmbito da PSE de Média Complexidade se reuniam em um encontro de supervisão para a discussão de temas que compõem o cotidiano dos CREAS e Centros POP, e dos casos acompanhados pelos psicólogos. Foi uma experiência pioneira e exitosa, além de demanda pelos psicólogos lotados naquela Secretaria (em sua maioria, através de contratos), que não teve continuidade com a chegada de uma nova gestão à Subsecretaria de Proteção Social Especial/SMA no início de 2013.

9. No sentido de pathos, isto é, de padecimento - no caso, consentido. Mas, também, de adesão irrestrita. 